\title{
The Influence of Emotional Labor on Job Involvement in Taiwan's Convenience Store: Compare the Effects of Moderating Role Among PJ Fit, PO Fit, PS Fit, and PG Fit
}

\author{
Shih-Kai Lin ${ }^{1} \&$ Ping-Fu Hsu ${ }^{2}$ \\ 1 Ph.D. Candidates, Department of Business Administration, National Yunlin University of Science \& \\ Technology, Yunlin, Taiwan \\ ${ }^{2}$ Assistant Professor, International College, Krirk University, Krung Thep Maha Nakhon, Thailand \\ Correspondence: Shih-Kai Lin, Ph.D. Candidates, Department of Business Administration, National Yunlin \\ University of Science \& Technology, 123 University Road, Section 3, Douliou, Yunlin 64002, Taiwan. E-mail: \\ sklin1105@yahoo.com.tw
}

Received: March 14, 2021

Accepted: March 26, 2021

Online Published: April 9, 2021

doi:10.20849/ajsss.v6i1.868

URL: https://doi.org/10.20849/ajsss.v6i1.868

\begin{abstract}
Research on emotional labor focus on related employees' work outcomes, well-beings, and dissonances that could be ignored some moderation effects especially between emotional labor and job involvement. This study focused on difference types of PE fit that individual fit takes a moderation role between emotional labor and job involvement. Data from 230 convenience store full time (71.7\%) and part time (28.3\%) working employees were collected. Results indicate that difference types of PE fit predicated moderating effects influenced the relationship between predictor (emotional labor) and criterion variables (job involvement). In sum, in describing PE fit mediating the relationships between emotional labor and job involvement, Further, we have made the points that (a) emotional labor can indirectly influence job involvement by the mediating processes of perceived person-environment, (b) person-environment fit revealed partially mediating effects on the relationship between emotional labor and job involvement, (c) among emotional labor, PE fit, and job involvement regarding significance positive effects.
\end{abstract}

Keywords: emotional labor, PE fit, job involvement, job identity, job participation

\section{Introduction}

Occurring in "face-to-face" or "voice-to-voice" interactions with customers (Hochschild, 1983), emotional labor is central to many service occupations where employees are the first point of contact customers have with the organization that have been studied over three decades (Gabriel, Daniels, Diefendorff, \& Greguras, 2015). Emotional labor is the management of feeling to create a publicly observable facial and bodily display; emotional labor is sold for a wage and therefore has exchange value (Hochschild, 1983).

Many recent studies have focus on the emotional labor process (e.g., Grandey, 2000), which includes the perception of emotional display rules (i.e., emotional demands from the workplace), the perception of intrapsychic experiences (i.e., emotion regulation tend to be self-reported; Grandey, Dieffendorff, \& Rupp, 2013). Broadly speaking, studies often emphasize one part of this process, with much of works focused on regulating both feelings and expressions for organizational goals (Grandey, 2000).

To date, the most common way to examine these emotional labor process is to conduct employees' self-report and to examine the relationships of each response with predictors and criterions (e.g., Brotheridge \& Lee, 200.; Diefendorff, Croyle, \& Gosserand, 2005; Grandey, 2003). Measuring emotional labor occupation how to influence outcome variables has been sought to work related outcome, such as organizational commitment, job satisfaction and turnover (i.e., Grandey, 2003; Totterdell \& Holman, 2003). Few study conducted to job involvement which $\mathrm{Wu} \&$ Cheng (2006) noted the interaction relationship between job involvement and emotional labor. No evidence to examine the direct relationship between emotional labor and job involvement. These ideas suggest that types of mediator between emotional labor and job involvement likely exist.

If employees perceived person-environment fit that can improve their high degree job involvement and 
organizational commitment. As Rafaeli \& Sutton (1987) addressed emotional labor causes positive affect in some condition. They pointed out when employees expressed feelings are congruent with experienced emotions that causes experienced emotional harmony. That is the index of congruence between individual ability and work demand. However, employees' emotional behavior can fulfill organizational demands and experienced their inner truth feelings that is the perspective of positive emotional labor which will be matched the perceived emotional demands-abilities fit theory.

Whether the employees carry out their job involvement or not, except employees' professionals and traits, they need to consider the congruence with environment then cause match (Goštautaitè \& Bučiūnienè, 2010). In addition, the fit between individual and environment factors that is P-E fit (person-environment fit). The studies of person-environment fit have ignited from post 1980's, several researchers invest aged person-job fit and person-organization fit as their main variables (Kristof-Brown, Zimmerman, \& Johnson, 2005). Furthermore, a lot of research works have been done in this field to seek for well person-environment fit could result positive significance correlated among job attitude, behavior and work performance (O’Reilly et al., 1991; Cable, \& Judge, 1996; Kristof-Brown et al., 2005).

Kristof-Brown \& Billsberry (2013) have divided the P-E fit literatures into two categories, one is the employees' perspective emphasized direct perceived fit (Cable \& DeRue, 2002), and the other is examined the difference between person and environment, that emphasized indirect fit (also reciprocal fit; Chung, Shen, \& Judge, 2015). They noted both of the field studies are compensative not competitive. This study attempts to address the perspective of personal direct fit and measure different environment aspects. There is no empirical study in Taiwan concern in the moderating roles of perceived person - environment fit between emotional labor and job involvement. Up to this point, however, there were few empirical studies of the effects of positive emotional labor on job involvement of chain convenience store's employees. Thus, this paper will focus on a conceptual framework of person-environment fit for examining the influences and relationships between emotional labor and job involvement.

Schaubroeck \& Jones (2000) addressed that perceived emotional labor and employees' healthy are moderated by emotional adaptability and work attitude (i.e., job involvement, organizational identity). Similar examples abound in the literature. Such as Lyubomirsky, King, \& Diener (2005) noted in their study of positive emotion in employee's attitude, "employees experienced positive emotion cause higher involvement, organizational citizen behavior and performance, meanwhile reduce they experienced dissonance. Besides, how will measure the degree of fits between employees' attributions (i.e., demand, value, capacity and individual characteristics) and environment attributions (i.e., value, reward, work requirement, culture and material environment) that is an important factor effects employees' attitudes and behaviors.

In the workplace, how will employees manage their emotional rules? What is the effects of emotional labor on job involvement? To what extent is person-environment fit mediator effects to emotional labor and job involvement?

The purpose of this paper is therefore twofold:

(1) To explore the relationships between emotional labor and job involvement.

(2) To draw on the mediator effects of perceived person-environment fits between emotional labor and job involvement.

\section{Emotional Labor}

Emotional labor is "the management of feeling to create a publicly observable facial and bodily display" occurring in face-to-face or voice-to-voice interactions with customers. Hochschild (1983) examines the cost of this kind of "emotional labor." It means just sold for wage, also concern interacted with others and self. People's feeling is a genuine and display spontaneously. Ekman \& Friesen (1999) even puts out, we can recognize the true of genuine or not from people face detail.

Grandey et al. (2013) provide and excellent review of comparing the definitions, measurement, and outcomes of the emotional labor theory three lenses: (1) EL as occupational requirements, (2) EL as emotional displays, and (3) EL as intra-psychic processes. Contrast to Grandey \& Gabriel (2015) also reviewed emotional labor literature on organizational behavior and organizational psychology, they look EL as a dynamic integration and sorted EL to three components, (1) emotional job requirements, (2) emotion regulation, and (3) emotional performance. These reviews appear to a lot of research works have been done in this field to seek for a reliability measurement. In spite of these literatures show that EL research context from work requirements, emotional display to intra-psychic, but we can see in all center research on emotional labor, including: (1) display rules, (2) emotional dissonance, (3) 
surface acting and deep acting, and (4) the frequency, duration, and variety of interactions in the job (Morris \& Feldman, 1996). To date, however, no clear direction has emerged to suggest which moderators would influence between emotional labor and job involvement.

\subsection{The Operational Concept of Emotional Labor}

Due to Hochschild (1983) offered the perspective of feeling management, surface acting (SA) and deep acting (DA) prolonged a series of multidimensional concepts, such as Morris \& Feldmans' (1996) perspective of control and planning provided four concepts. Grendy (2000) offered the two concepts from emotional regulation strategy and Brotheridge \& Lees' (2003) the scale of six concepts. Overall these concepts provided all map of emotional labor, the following we'll show more detail, especially the scale was developed by Taiwan's scholar, Shang-Ping, Lin.

\subsection{Emotional Labor and Job Involvement}

Lodahl \& Kejners' (1965) perspective of job involvement origins from the point of individual versus ego involvement in work and the point of view from socialist's central life interests. Kanungo (1982) defined job involvement is individual thinks the importance of work upon identity or belief in psychology, namely, individual presents the degree of identity and commitment on own job. According to Kanungo's (1982) point of view that the main concepts of jog involvement includes job identity and job participation.

Job involvement are influences by individual characteristics, job features (i.e., emotional labor high or low), supervisor variable, and character recognition (Brown, 1996). One of the variable of job features is autonomy that effect employees' emotional labor directly, when they have high autonomy or better self-control ability and they wouldn't meet emotional dissonance (Wharton, 1993). Accordingly, we proposed that employees toward the positive emotion even they load high emotional labor, they would improve their job involvement.

Regarding positive emotional labor that attribute employees' psychological capital, Avey, Luthans, \& Youssef (2010) describes as psychological capital is an important individual resource that improve individual development and job involvement in workplace. It is likely that the results of such studies would have significant theoretical importance. More important except positive emotional labor show positive correlation between emotional labor and job involvement (i.e., Yoo \& Arnold; Siu et al., 2014), with potential moderating influence between them. Notwithstanding the positive emotion more likely enhances employees' job involvement (Yeh, 2018), but higher emotional labor decreases employees' job involvement (Hsu, 2015). Further we have to think over any moderator influence among them. Therefore, we propose the following hypothesis:

\section{Hypothesis 1: Emotional labor has a direct and positive or negative influenced on job involvement.}

\subsection{Perceived Person-Environment Fit: The Mediator Between Emotional Labor and Job Involvement}

Fit or mis-fit perspective between person (P) variables (i.e., capability, demand, and value etc.) and environment (E) variables (i.e., job demand, job attribution, social environment, and organizational culture etc.) which lead to positive or negative results (Edwards, 2008; Kristof, 1996; Schneider, 2001). Contemporary person-environment research come from Parson's (1909) study occupational psychology, matching model and congruence concept that is career decision making model.

A lot of person-environment fit theories and empirical studies that assume to base person-environment per se the coincide results, such as job satisfaction, organizational commitment, and job performance (Kristor-Brown et al., 2005; O'Reilly). The point is interaction between person and environment concerning congruence degree. Recently, P-E Fit theory has been classified two research categories, the one is emphasize perceived direct fit from employees' view and the other is indirect fit, namely, measure fit from person and environment individually (Kristof-Brown \& Billsberry, 2013). Base on the perspective of complementary fit, perceived fit, emotional regulation mechanism, and self-regulation theory, we propose P-E fit would mediate the relationship between emotional labor and job involvement.

By the way, almost person-environment fit theory employ twofold dimensions to measure with work related variables, including person-organization, and person-job fits (e.g., perceived fit; Chuang et al., 2015). With the expectation of measuring double dimensions such as person-group, and person-supervisor fit (e.g., reciprocal fit; Chuang et al., 2015) researchers always use each dimension to investigate fit degree (Herdman \& Carlson, 2009). Without expectation, people always interacted with multiple environments, for example, Lewin (1935) provided person-environment interaction theory to illustrate people influence on environment all the time.

Now we head to multiple dimensions P-E fit concepts. Kristof-Brown et al. (2005) offered a quantity study to explore multiple dimension concepts. In their literature review provided that different types of fit including 
person-group, person-supervision, person-job, and person-organization fits to measure people ante-organization, within-organization, and turnover. This is not to say that these the key aspects of the combination all type of fits. But we propose that each fit would mediate every employee when they involve emotion in workplace. Regarding perceived fit (PO, PJ fit) and reciprocal fit (PS, PG fit) we propose the following hypothesis:

Hypothesis 2: Emotional labor has a direct and positive influenced on PE fit.

Hypothesis 3: PE fit has a direct and positive influenced on job involvement.

Hypothesis 4: Person-environment fit (PJ, PO, PS, PG fit) reveal mediating effects on the relationship between emotional labor and job involvement.

\subsection{Research Framework}

According to this study of purpose and discussed literatures, we provide this research framework as Figure 1:

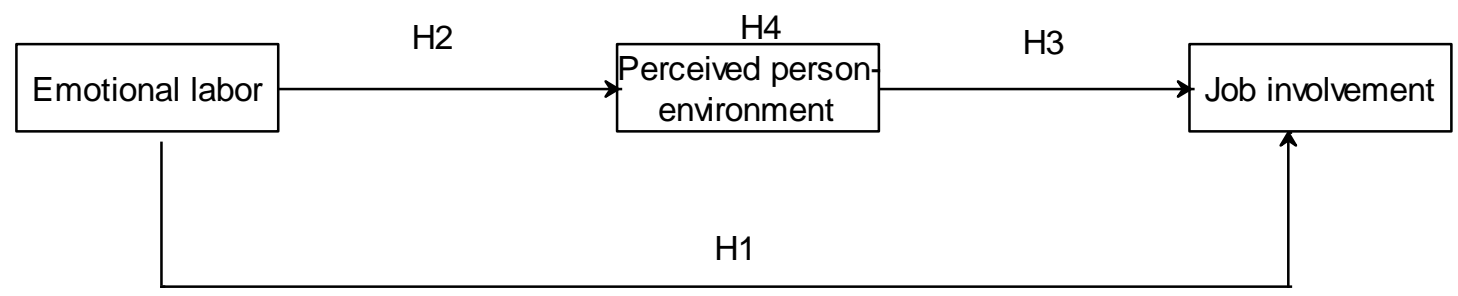

Figure 1. Research framework

\section{Method}

Data from $230($ male $=78$; female $=152)$ convenience store in Taiwan were used in present study. Participants completed the questionnaires in the workplace environment. Participants did not place their names on the measures and were confident of the confidentiality of their responses.

Employees rates the three constructs of emotional labor scare (Lin, 2000), two constructs of job involvement (Kanungo, 1982) and four constructs of PE fit (Cable \& DeRue, 2002; Lauver \& Kristof-Brown, 2001; Saks \& Ashforth, 1997). The following domain scales containing 51 items were distinguished, (alphas, CR, and AVE among parentheses): (1) Basic emotional display (.864; .796; .362): describes employee's emotional labor getting high and show that the emotional burden getting high. (2) Surface emotion control (.865; .667; .406): shows worker's surface emotional control is high, it represents their emotional burden is high. (3) Deep acting $(.874 ; .811 ; .383)$ : pointed when the workers execute emotional missions they need more efforts to control their true feelings. (4) Job identity $(.862 ; .611 ; .301)$ : illustrates employees' cognition with their job. (5) Job participation $(.867 ; .643 ; .390)$ : describes employees engaged the degree of job. (6) PJ fit $(.862 ; .790 ; .359)$ : covers the congruence between employees and jobs. (7) PO fit $(.866 ; .866 ; .522)$ : describes the fit between employees and organization. (8) PS fit $(.859 ; .867 ; .491)$ : illustrates the congruence between employees and supervisors. (9) PG fit $(.864 ; .820 ; .437)$ : covers the congruence between employees and group. All scale items were measured on 5-point Likert scale.

A confirmatory factor analysis (maximum likelihood estimation; Amos 21.0) including all items scales confirms the measurement models (see Table 1). The Fornell and Larcker (1981) test provides evidence for discriminant validity. We applied several methods ex ante (before) and ex post (after) to avoid common method variance (Podsakoff, Mackenzie, Lee, \& Podsakoff, 2003). Ex ante we used both separation approach of data collecting and design approach of instrument developing. As ex post means of control, the single-factor test was run. An exploratory factor analysis including all indicators reveals that many factors explain $66.247 \%$ of the variance. By contrast, one general factor explains $27.016 \%$ of the variance only. Hence, this study doesn't exist common method variance.

This study conducted all variables correlations analysis including means and standard deviations. Regression analysis was applied to measure the relationship between predictors and outcome variables. Then, we used the mediator approach proposed by Preacher and Hayes (2004, 2008) and Hayes (2012), including a bootstrapping procedure for testing the indirect effects. At last, for probing interactions, we followed Hayes \& Matthes (2009) which identifies direct and indirect effect of the mediator variable where the effect of the focal variable on the outcome is statically significant and not significant. 


\section{Result}

All variables models of fit goodness index are reported in Table 1. We followed Hu and Bentler (1998) suggested the goodness index standard values, except PPJ fit of NNFI $=.858$, RMSEA $=.107$, and SRMR $=.0587$ are out of little range, others represented well goodness. Bivariate correlations are presented in Table 2. All variables are provided significance.

In general, as observed in Figure 2, the mediator of low PPE offers horizontal line means that high and low emotional labor would not influence on job involvement.

In contrast, high PPE group would be effected the relationship between emotional labor and job involvement.

Table 1. Fit index of variables model

\begin{tabular}{lccccccccc}
\hline $\begin{array}{l}\text { Variabl } \\
\mathrm{e}\end{array}$ & $X^{2}$ & $X^{2} / d f$ & NFI & NNFI & CFI & GFI & AGFI & $\begin{array}{c}\text { RMSE } \\
\mathrm{A}\end{array}$ & SRMR \\
\hline $\mathrm{BE}$ & 51.761 & 3.697 & 0.874 & 0.855 & 0.903 & 0.939 & 0.878 & 0.109 & 0.0588 \\
$\mathrm{SA}$ & 0 & 0 & 1 & - & 1 & 1 & - & 0.377 & 0 \\
$\mathrm{DA}$ & 20.47 & 1.462 & 0.951 & 0.975 & 0.984 & 0.975 & 0.950 & 0.045 & 0.0345 \\
\hline $\mathrm{JI}$ & 62.586 & 12.517 & 0.716 & 0.453 & 0.726 & 0.908 & 0.724 & 0.224 & 0.1089 \\
$\mathrm{JP}$ & 29.565 & 5.913 & 0.894 & 0.816 & 0.908 & 0.952 & 0.855 & 0.146 & 0.0668 \\
\hline PPJ & 50.512 & 3.608 & 0.876 & 0.858 & 0.906 & 0.939 & 0.878 & 0.107 & 0.0587 \\
$\mathrm{PPO}$ & 35.146 & 3.905 & 0.941 & 0.925 & 0.955 & 0.951 & 0.885 & 0.113 & 0.0402 \\
$\mathrm{PPS}$ & 30.667 & 2.191 & 0.955 & 0.962 & 0.975 & 0.963 & 0.925 & 0.072 & 0.0336 \\
$\mathrm{PPG}$ & 37.081 & 4.120 & 0.916 & 0.890 & 0.934 & 0.948 & 0.878 & 0.117 & 0.0455 \\
\hline value & $>.1$ & $<5$ & $>.9$ & $>.9$ & $>.9$ & $>.9$ & $>.8$ & $<0.1$ & $<.05$ \\
\hline
\end{tabular}

Hypothesis 1 (see Table 3) tests the relationship between emotional labor and job involvement that represented $\mathrm{BE}$ to job identity $(\mathrm{Beta}=.344 ; \mathrm{p}<.000)$, DA to job participation (Beta $=.223 ; \mathrm{p}<.05)$, and both general models showed significance. The variance inflation factor (VIF) are lower than 5 that means the tolerance value under 2 (Belsley, 1991; Belsley, Kuh, \& Welsch, 1980). Hypothesis 2 tests the relationship between emotional labor and person-environment fit that described EL to PE (Beta $=.684 ; \mathrm{p}<.000)$. Hypothesis 3 tests the relationship between person-environment fit and job involvement that represented PE to JINVO (Beta $=.637 ; \mathrm{p}<.000$ ).

Table 2. Pearson correlations, mean and $\mathrm{SD}$ of the all variables $(\mathrm{N}=230)$

\begin{tabular}{|c|c|c|c|c|c|c|c|c|c|c|c|c|c|c|}
\hline Variable & Mean & S.D. & EL & JINVO & PE & $\mathrm{BE}$ & SA & DA & JI & $\mathrm{JP}$ & PPJ & PPO & PPS & PPG \\
\hline EL & 4.005 & .450 & 1 & & & & & & & & & & & \\
\hline JINVO & 3.333 & .540 & $.428 * *$ & 1 & & & & & & & & & & \\
\hline PE & 3.768 & .498 & $.684^{* * *}$ & $.637 * *$ & 1 & & & & & & & & & \\
\hline $\mathrm{BE}$ & 4.080 & .482 & $.831 * *$ & $.414 * *$ & $.587 * *$ & 1 & & & & & & & & \\
\hline SA & 4.017 & .584 & $.878^{* * *}$ & $.333^{* *}$ & $.528^{*}$ & $.635^{* *}$ & 1 & & & & & & & \\
\hline DA & 3.918 & .536 & $.815^{* *}$ & $.343^{* *}$ & $.621^{* *}$ & $.503^{* *}$ & $.552^{* * *}$ & 1 & & & & & & \\
\hline JI & 3.548 & .558 & $.447 * *$ & $.774 * *$ & $.592^{* *}$ & $.439 * *$ & $.333 * *$ & $.367 * *$ & 1 & & & & & \\
\hline JP & 3.331 & .731 & $.322 * *$ & $.800 * *$ & $.523 * *$ & $.258 * *$ & $.283 * *$ & $.270 * *$ & $.753 * *$ & 1 & & & & \\
\hline PPJ & 3.696 & .575 & $.536^{* * *}$ & $.688^{* *}$ & $.812 * *$ & $.502 * *$ & $.459 * *$ & $.466^{*}$ & $.637 * *$ & $.568^{* * *}$ & 1 & & & \\
\hline $\mathrm{PPO}$ & 3.623 & .662 & $.481 * *$ & $.485^{* *}$ & $.825^{* *}$ & $.441 * *$ & $.333^{* * *}$ & $.452 * *$ & $.448^{* * *}$ & $.381 * *$ & $.553 * *$ & 1 & & \\
\hline PPS & 3.834 & .615 & $.635^{* * *}$ & $.471^{* *}$ & $.852 * *$ & $.540 * *$ & $.498 * *$ & $.571 * *$ & $.425^{* * *}$ & $.396^{* * *}$ & $.551 * *$ & $.608 * *$ & 1 & \\
\hline PPG & 3.919 & .546 & $.606^{* *}$ & $.481 * *$ & $.834 * *$ & $.469 * *$ & $.477 * *$ & $.583 * *$ & $.466^{* * *}$ & $.403 * *$ & $.618 * *$ & $.529 * *$ & $.666^{* *}$ & 1 \\
\hline
\end{tabular}

Note: $* \mathrm{p}<.05 ; * * \mathrm{p}<.01$ 
Table 3. Summary of linear regression for EL predicting job involvement

\begin{tabular}{|c|c|c|c|c|c|c|c|}
\hline \multirow{2}{*}{$\begin{array}{l}\text { Criterion=PE } \\
\text { Predictor }\end{array}$} & \multicolumn{2}{|c|}{ unstandardized } & \multicolumn{2}{|c|}{ standard } & \multicolumn{3}{|c|}{ collinearity diagnostics } \\
\hline & $\boldsymbol{\beta}$ & SE & Beta & $\mathrm{t}$ & $\mathrm{p}$ & Tolerance & VIF \\
\hline constant & .734 & .215 & & 3.409 & .001 & & \\
\hline EL & .758 & .053 & .684 & 14.174 & .000 & 1.000 & 1.000 \\
\hline General Model & $\mathrm{R}^{2}=.468$ & Adjusted $\mathrm{F}$ & $=.466$ & $\mathrm{~F}=200.911$ & $\mathrm{p}<.000$ & & \\
\hline Criterion=JINVO & \multicolumn{2}{|c|}{ unstandardized } & \multicolumn{2}{|c|}{ standard } & \multicolumn{3}{|c|}{ collinearity diagnostics } \\
\hline Predictor & $\beta$ & SE & Beta & $\mathrm{t}$ & $\mathrm{p}$ & Tolerance & VIF \\
\hline constant & .732 & .210 & & 3.481 & .001 & & \\
\hline PE & .690 & .055 & .637 & 12.469 & .000 & 1.000 & 1.000 \\
\hline General Model & $\mathrm{R}^{2}=.405$ & Adjusted $\mathrm{R}$ & $=.403$ & $\mathrm{~F}=155.473$ & $\mathrm{p}<.000$ & & \\
\hline Criterion $=\mathrm{JI}$ & \multicolumn{2}{|c|}{ unstandardized } & \multicolumn{2}{|c|}{ standard } & \multicolumn{3}{|c|}{ collinearity diagnostics } \\
\hline Predictor & $\beta$ & SE & Beta & $\mathrm{t}$ & $\mathrm{p}$ & Tolerance & VIF \\
\hline constant & 1.148 & .330 & & 3.485 & .001 & & \\
\hline $\mathrm{BE}$ & .419 & .098 & .344 & 4.258 & .000 & .563 & 1.775 \\
\hline SA & .030 & .084 & .030 & .357 & .721 & .524 & 1.907 \\
\hline DA & .085 & .082 & .078 & 1.038 & .300 & .657 & 1.522 \\
\hline General Model & $\mathrm{R}^{2}=.168$ & \multicolumn{2}{|c|}{ Adjusted $\mathrm{R}^{2}=.157$} & $\mathrm{~F}=15.210$ & $\mathrm{p}<.000$ & & \\
\hline Criterion $=\mathrm{JP}$ & \multicolumn{2}{|c|}{ unstandardized } & \multicolumn{2}{|c|}{ standard } & \multicolumn{3}{|c|}{ collinearity diagnostics } \\
\hline Predictor & $\beta$ & SE & Beta & $\mathrm{t}$ & $\mathrm{p}$ & Tolerance & VIF \\
\hline constant & 1.105 & .331 & & 3.340 & .001 & & \\
\hline $\mathrm{BE}$ & .246 & .099 & .201 & 2.492 & .013 & .563 & 1.775 \\
\hline SA & .070 & .084 & .070 & .834 & .405 & .524 & 1.907 \\
\hline DA & .246 & .082 & .223 & 2.989 & .003 & .657 & 1.522 \\
\hline General Model & $\mathrm{R}^{2}=.175$ & Adjusted $\mathrm{R}$ & $=.164$ & $\mathrm{~F}=15.933$ & $\mathrm{p}<.000$ & & \\
\hline
\end{tabular}

Note $\mathrm{PE}=$ person-environment fit; $\mathrm{EL}=$ emotional labor; JINVO = job involvement;

$\mathrm{BE}=$ basic emotion displays; $\mathrm{SA}=$ surface emotion control; $\mathrm{DA}=$ deep acting.

Mediating effects of person-environment fit on the relationship between emotional labor and job involvement are shown in Table 4 and Figure 2. The influence of emotional on labor job involvement both direct and indirect levels. The indirect level of the influence of emotional labor on job involvement through person-environment was 1.054. In addition, direct levels of the influence of emotional labor on job involvement reached the significance level. Person-environment fit revealed partially mediating effects on the relationship between emotional labor and job involvement. The results showed that emotional labor can indirectly influence job involvement through mediating processes of person-environment fit.

Mediating effects of person-environment fit on the relationship between emotional labor and job involvement are shown in Table 4 and Figure 2. The results demonstrated a significant relationship between independent variables and mediators; there were significant relationships between mediators and dependent variables. Direct levels of the influence of person-environment fit on job involvement reached significant levels, indicating the partially mediating effects of emotional labor and job involvement. In other words, the influence of person-environment fit on job involvement involves both direct and indirect levels. The indirect level (.531) was more significant than the direct level (-.017). According to the results, emotional labor can indirectly influence job involvement by the mediating processes of perceived person-environment. Thus, Hypothesis 4,"perceived person-environment reveal mediating effects on the relationship between emotional labor and job involvement," was supported by this study. 
Table 4. Direct \& indirect effects \& $95 \%$ confidence intervals for meditational model

\begin{tabular}{|c|c|c|c|c|c|}
\hline \multirow[t]{2}{*}{ Model pathways } & \multirow[t]{2}{*}{ Effect } & \multirow[t]{2}{*}{$\mathrm{SE}$} & \multirow[t]{2}{*}{$\mathrm{t}$ value } & \multicolumn{2}{|c|}{$95 \% \mathrm{CI}$} \\
\hline & & & & LLCI & ULCI \\
\hline \multicolumn{6}{|l|}{ Total Effects } \\
\hline $\mathrm{EL} \rightarrow \mathrm{PE} \mathrm{fit} \rightarrow \mathrm{JI}$ & $.514^{*}$ & .072 & 7.155 & .372 & .655 \\
\hline \multicolumn{6}{|l|}{ Direct Effects } \\
\hline $\mathrm{EL} \rightarrow \mathrm{PE} \mathrm{fit} \rightarrow \mathrm{JI}$ & -.017 & .084 & -.204 & -.183 & .149 \\
\hline Indirect Effects & \multicolumn{5}{|c|}{ Boot SE } \\
\hline $\mathrm{EL} \rightarrow \mathrm{PE} \mathrm{fit} \rightarrow \mathrm{JI}$ & $.531 *$ & & 69 & .416 & .683 \\
\hline \multicolumn{6}{|c|}{ Partially indirect effect } \\
\hline $\mathrm{EL} \rightarrow \mathrm{PE} \mathrm{fit} \rightarrow \mathrm{JI}$ & $.982 *$ & & 06 & .782 & 1.205 \\
\hline \multicolumn{6}{|c|}{ Completely indirect effect } \\
\hline $\mathrm{EL} \rightarrow \mathrm{PE} \mathrm{fit} \rightarrow \mathrm{JI}$ & $.442 *$ & & 51 & .350 & .549 \\
\hline \multicolumn{6}{|c|}{ Ratio of indirect to direct } \\
\hline $\mathrm{EL} \rightarrow \mathrm{PE}$ fit $\rightarrow \mathrm{JI}$ & -30.972 & & 25 & .699 & 1.579 \\
\hline \multicolumn{6}{|c|}{ R-squared mediation effect } \\
\hline $\mathrm{EL} \rightarrow \mathrm{PE}$ fit $\rightarrow \mathrm{JI}$ & .183 & & 60 & .063 & .296 \\
\hline
\end{tabular}

Note. ${ }^{*}$ Empirical $95 \%$ confidence interval does not overlap with zero

$\mathrm{PE}$ fit = person-environment fit; $\mathrm{EL}=$ emotional labor; $\mathrm{JI}=$ job involvement

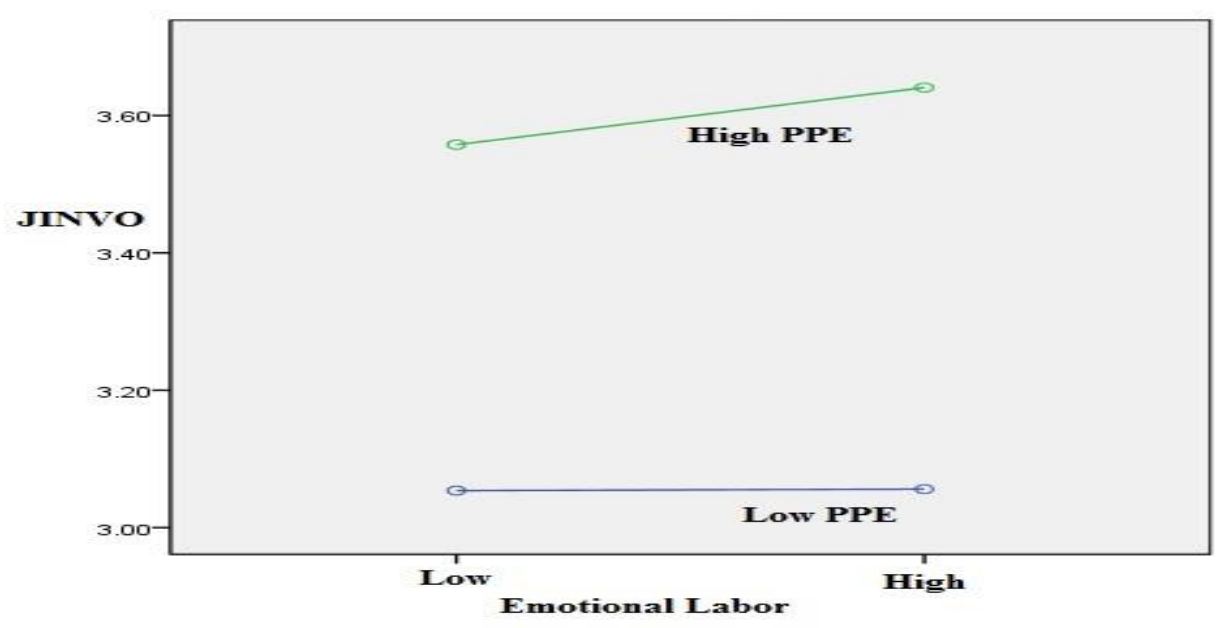

Figure 2. Mediating effects of PE fit

\section{Discussion and Conclusions}

In sum, in describing PE fit mediating the relationships between emotional labor and job involvement, we have made the points that (a) emotional labor can indirectly influence job involvement by the mediating processes of perceived person-environment, (b) person-environment fit revealed partially mediating effects on the relationship between emotional labor and job involvement, (c) among emotional labor, PE fit, and job involvement regarding significance positive effects.

All evidences revealed that Diefendorff (2014) noted perceived emotional demand-ability fit distinguished to other fits (i.e., PO, PS, PG, PJ fit) that evidenced PE fit would be mediated the relationship between emotional labor and job involvement. Obviously, partially indirect effect is the strongest mediated the relationship between 
emotional labor and job involvement. All in all, Niven, Totterdell, Holman, \& Cameron (2013) provided that third parties are individuals who become indirectly or directly involved in the emotional labor interaction between agent and target. That is agent might be PE fit and target should be job involvement which provided direct evidence be determined by self-determined.

As with any research, this study has limitations. All measures were collected from the same source. Future studies should collect data from additional source Further, within our data were merely presented that convenience store industry, future work may consider testing other industries. Finally, to fully understand emotional labor, the specific cultural contexts in which it takes place will need to be considered (Mesquita \& Delvaux, 2013). A fruitful future direction would be think over whether different culture and generation effects on emotional labor or not.

\section{References}

Avey, J. B., Luthans, F., \& Youssef, C. M. (2010). The additive value of positive psychological capital in predicting work attitudes and behaviors. Journal of Management, 36(2), 430-452.

Belsley, D. A. (1991). A guide to using the collinearity diagnostics. Computer Science in Economics and Management, 4(1), 33-50.

Belsley, D. A., Kuh, E., \& Welsch, R. E. (1980). Regression diagnostics: Identifying influential data and sources of collinearity. John Wiley: New York.

Brotheridge, C. M., \& Lee, R. T. (2003). Development and validation of the emotional labour scale. Journal of Occupational and Organizational Psychology, 76(3), 365-379.

Brown, S. P. (1996). A meta-analysis and review of organizational research on job involvement. Psychological Bulletin, 120(2), 235-255.

Cable, D. M., \& DeRue, D. S. (2002). The convergent and discriminant validity of subjective fit perceptions. Journal of Applied Psychology, 87(5), 875-884.

Cable, D. M., \& Judge, T. A. (1996). Person-organization fit, job choice decisions, and organizational entry. Organizational behavior and human decision processes, 67(3), 294-311.

Chuang, A., Shen, C. T., \& Judge, T. A. (2015). Development of a Multidimensional Instrument of PersonEnvironment Fit: The Perceived Person-Environment Fit Scale (PPEFS)[Electronic version]. Applied Psychology: An International Review, 65(1), 66-98.

Diefendorff, J. M., Croyle, M. H., \& Gosserand, R. H. (2005). The dimensionality and antecedents of emotional labor strategies. Journal of vocational behavior, 66(2), 339-357.

Diefendorff, J. M., Greguras, G. J., \& Fleenor, J. (2016). Perceived emotional demands-abilities fit. Applied Psychology, 65(1), 2-37.

Edwards, J. R. (2008). Person-environment fit in organizations: An assessment of theoretical progress. Academy of Management Annals, 2(1), 167-230.

Ekman, P., \& Friesen, W. V. (1974). Detecting deception from the body or face. Journal of Personality and Social Psychology, 29(3), 288-298.

Fornell, C., \& Larcker, D. F. (1981). Evaluating structural equation models with unobservable variables and measurement error. Journal of Marketing Research, 18(1), 39-50.

Gabriel, A. S., Daniels, M. A., Diefendorff, J. M., \& Greguras, G. J. (2015). Emotional labor actors: A latent profile analysis of emotional labor strategies. Journal of Applied Psychology, 100(3), 863-879.

Goštautaitė, B., \& Bučiūnienè, I. (2010). Integrating job characteristics model into the person environment fit framework. Economics and Management, 15(1), 505-511.

Grandey, A. A. (2000). Emotional regulation in the workplace: A new way to conceptualize emotional labor. Journal of occupational health psychology, 5(1), 95-110.

Grandey, A. A. (2003). When "the show must go on": Surface acting and deep acting as determinants of emotional exhaustion and peer-rated service delivery. Academy of management Journal, 46(1), 86-96.

Grandey, A. A., \& Gabriel, A. S. (2015). Emotional labor at a crossroads: Where do we go from here?. Annual Review of Organizational Psychology and Organizational Behavior.

Grandey, A. A., Diefendorff, J. M., \& Rupp, D. E. (2013). Bringing emotional labor into focus: A review and integration of three research lenses. In Grandey, A. A., Diefendorff, J. M., \& Rupp, D. E. (Eds.), Emotional 
Labor in the 21st Century: Diverse Perspectives on Emotion Regulation at Work (pp. 3-27). Psychology Press/Routledge: New York.

Hayes, A. F. (2012). PROCESS: A versatile computational tool for observed variable mediation, moderation, and conditional process modeling. [White paper]. Retrieved from http://www.afhayes.com/public/process2012.pdf

Hayes, A. F., \& Matthes, J. (2009). Computational procedures for probing interactions in OLS and logistic regression: SPSS and SAS implementations. Behavior Research Methods, 41(3), 924-936.

Herdman, A. O., \& Carlson, K. D. (2009). Global perceptions of the fit between person and work environment (PE fit): Development and initial validation of a new measure. Psychological Reports, 105(3), 1181-1195.

Hochschild Arlie, R. (1983). The managed heart: Commercialization of human feeling. Berkeley, University of California Press.

Hu, L., \& Bentler, P. (1999). Cutoff criteria for fit indexes in covariance structure analysis: convenfional criteria versus new alternatives. Structural Equation Modeling: A Multidisciplinary Journal, 6(1), 1-55.

Kanungo, R. N. (1982). Measurement of job and work involvement. Journal of Applied Psychology, 67(3), 341-349.

Kristof, A. L. (1996). Person-organization fit: An integrative review of its conceptualizations, measurement, and implications. Personnel Psychology, 49(1), 1-49.

Kristof-Brown, A. L., \& Billsberry, J. (2013). Fit for the future. In Kristof-Brown, A. L., \& Billsberry, J. (Eds.), Organizational fit: Key issues and new directions (pp. 1-18). John Wiley \& Sons: New York.

Kristof-Brown, A. L., Zimmerman, R. D., \& Johnson, E. C. (2005). Consequences of individuals' fit at work: A meta-analysis of person-job, person-organization, person-group, and person-supervisor fit. Personnel psychology, 58(2), 281-342.

Lauver, K. J., \& Kristof-Brown, A. (2001). Distinguishing between employees' perceptions of person-job and person-organization fit. Journal of Vocational Behavior, 59(3), 454-470.

Lewin, K. (1935). A dynamic theory of personality. McGraw-Hill: New York, NY, US.

Lin, S. (2000). The development organization emotional labor scale. Sun Yat-Sen Management Review, 3(8), 427-447.

Lodahl, T. M., \& Kejnar, M. (1965). The definition and measurement of job involvement. Journal of Applied Psychology, 49(1), 24-33.

Lyubomirsky, S., King, L., \& Diener, E. (2005). The Benefits of Frequent Positive Affect: Does Happiness Lead to Success?. Psychological Bulletin, 131(6), 803-855.

Mesquita, B., \& Delvaux, E. (2013). A cultural perspective on emotional labor. In Grandey, A. A., Diefendorff, J. M., \& Rupp, D. E. (Eds.), Emotional labor in the 21st century: Diverse perspectives on emotion regulation at work (1st ed., pp. 251-272). Psychology Press/Routledge: New York.

Morris, J. A., \& Feldman, D. C. (1996). The dimensions, antecedents, and consequences of emotional labor. Academy of Management Review, 21(4), 986-1010.

Niven, K., Totterdell, P., Holman, D., \& Cameron, D. (2013). Emotional labor at the unit-level. In Grandey, A. A., Diefendorff, J. M., \& Rupp, D. E. (Eds.), Emotional labor in the 21st century: Diverse perspectives on emotion regulation at work (pp. 101-123). Psychology Press/Routledge: New York.

O'Reilly III, C. A., Chatman, J., \& Caldwell, D. F. (1991). People and organizational culture: A profile comparison approach to assessing person-organization fit. Academy of Management Journal, 34(3), 487-516.

Parsons, F. (1909). Choosing a vocation. Houghton-Mifflin: Boston.

Podsakoff, P. M., Mackenzie, S. B., Lee, J. Y., \& Podsakoff, N. P. (2003). Common method biases in behavioral research: a critical review of the literature and recommended remedies. Journal of Applied Psychology, 88(5), 879-903.

Preacher, K. J., \& Hayes, A. F. (2004). SPSS and SAS procedures for estimating indirect effects in simple mediation models. Behavior Research Methods, Instruments, \& Computers, 36(4), 717-731.

Preacher, K. J., \& Hayes, A. F. (2008). Asymptotic and resampling strategies for assessing and comparing indirect effects in multiple mediator models. Behavior Research Methods, 40(3), 879-891. 
Rafaeli, A., \& Sutton, R. I. (1987). Expression of emotion as part of the work role. Academy of Management Review, 12(1), 23-37.

Saks, A. M., \& Ashforth, B. E. (1997). A longitudinal investigation of the relationships between job information sources, applicant perceptions of fit, and work outcomes. Personnel Psychology, 50(2), 395-426.

Schaubroeck, J., \& Jones, J. R. (2000). Antecedents of workplace emotional labor dimensions and moderators of their effects on physical symptoms. Journal of Organizational Behavior: The International Journal of Industrial, Occupational and Organizational Psychology and Behavior, 21(2), 163-183.

Schneider, S. L. (2001). In search of realistic optimism - Meaning, knowledge, and warm fuzziness. American Psychologist, 56(3), 250-263.

Totterdell, P., \& Holman, D. (2003). Emotion regulation in customer service roles: testing a model of emotional labor. Journal of occupational health psychology, 8(1), 55-73.

Wharton, A. S. (1993). The affective consequences of service work: Managing emotions on the job. Work and Occupations, 20(2), 205-232.

Wu, T.-Y., \& Cheng, B.-S. (2006). The effect of interactions among job involvement, ability of regulating other's emotion, and emotional labor on emotional exhaustion. Chinese Journal of Psychology, 48(1), 69-87.

Yeh, C. M. (2018). The relationship between free time activities, emotional intelligence and job involvement of frontline hotel employees. The International Journal of Human Resource Management, 1-22.

Yoo, J. J., \& Arnold, T. J. (2014). Customer orientation, engagement, and developing positive emotional labor. The Service Industries Journal, 34(16), 1272-1288.

\section{Copyrights}

Copyright for this article is retained by the author(s), with first publication rights granted to the journal.

This is an open-access article distributed under the terms and conditions of the Creative Commons Attribution license (http://creativecommons.org/licenses/by/4.0/). 